\title{
ASPECTOS RELEVANTES NA FORMAÇÃO DE MANIPULADORES DE ALIMENTOS QUE ATUAM NA ALIMENTAÇÃO ESCOLAR
}

\author{
Ana Luiza Sander Scarparo', Paula Leite Baldasso ${ }^{2}$, Elaine Ferreira da Silva Lopes ${ }^{3}$, \\ Fernanda Camboim Rockett ${ }^{4}$, Janaína Guimarães Venzke ${ }^{5}$
}

Resumo: Este trabalho tem como objetivo propor uma nova abordagem para as ações de formação destinadas aos manipuladores de alimentos que atuam na alimentação escolar, fornecendo subsídios que auxiliem os responsáveis pelo planejamento e execução destas formações, e, consequentemente, propiciem uma melhora na qualidade do Programa Nacional de Alimentação Escolar. A formação de manipuladores de alimentos constitui uma ação integrada e de responsabilidade de diversos atores ou seguimentos, que poderão contribuir de formas diversas, em diferentes etapas do processo da formação, principalmente, com suas experiências e conhecimentos específicos de sua área. Para a formação contínua dos manipuladores, sugere-se uma prática teórica metodológica fundamentada na Pedagogia Crítica da Educação, que traz como eixo a problematização e como ponto de partida a prática do planejamento participativo. Deve-se ter em mente que para efetivar a formação contínua serão necessárias ações a curto, médio e longo prazo, que estarão contempladas nas etapas de planejamento, de execução e de avaliação. Ao planejar uma formação deve-se levar em consideração, como eixos norteadores, que a alimentação escolar é um direito dos estudantes e constitui-se como um espaço pedagógico, no qual os manipuladores de alimentos possuem papel relevante, o qual deve ser valorizado. Aconselha-se que a formação dos manipuladores de alimentos tenha momentos individuais e coletivos, considerando o tempo de serviço, as vivências e as experiências dos funcionários, abordando assuntos para além das boas práticas na produção dos alimentos.

Palavras-chave: Educação Permanente. Alimentação Escolar. Formação Profissional.

1 Nutricionista, Doutora em Educação em Ciências: Química da Vida e Saúde pela Universidade Federal do Rio Grande do Sul - UFRGS. Atua no Centro Colaborador em Alimentação e Nutrição do Escolar - CECANE UFRGS. Contato: anascarparo@gmail.com.

2 Nutricionista, Contadora, Especialista em Nutrição Materno Infantil pelo Instituto de Educação e Pesquisa do Hospital Moinhos de Vento - HMV. Atua como Nutricionista Responsável Técnica pelo PNAE.Contato: paulabaldasso@hotmail.com

3 Pedagoga, Doutora em Educação - UFRGS. Contato: elainefs.lopes@terra.com.br

4 Nutricionista, Doutoranda em Ciência e Tecnologia de Alimentos - UFRGS. Contato: fernandarockett@gmail.com

5 Nutricionista, Doutora em Biotecnologia pela Universidade Federal de Pelotas - UFPel, Professora Associada do Departamento de Nutrição da UFRGS. Contato: janaina.venzke@ufrgs.br 


\title{
RELEVANT ASPECTS IN THE FORMATION OF FOOD HANDLERS WHO WORK IN SCHOOL FEEDING
}

\begin{abstract}
This article aims to propose a new approach to education actions destined to food handlers who work in school feeding, providing subsidies that may help the responsibles for its planning and execution and, consequently, to improve the quality of the Brazil's National School Feeding Programme. The education of food handlers is made of an integrated action that depends on several actors that are able to contribute in the different steps of the training process, specially with their experience and specific knowledge. In the context of continuing education of food handlers it is recommended to follow a theoretical method based on Critical Pedagogy, which brings problematization as the main axis and practice of collective planning as the first step. In order to effectively accomplish a continuing education, actions in the short, medium and long term will be taken into account on the stages of planning, execution and evaluation. School feeding is a student right and has a pedagogical function in which food handlers have a very relevant role - which must be recognized. It is recommended that the education keep providing food handlers self guided moments as well as collective ones, considering personal and professional experiences, taking into account subjects that go further than good practices in food production.
\end{abstract}

Keywords: Education. Continuing. School Feeding. Profissional Training.

\section{INTRODUÇÃO}

A alimentação adequada é direito fundamental do ser humano, consagrado na Constituição Federal (BRASIL, 1988), devendo o poder público adotar políticas e ações que se façam necessárias para promover e garantir a Segurança Alimentar e Nutricional (SAN) da população (BRASIL, 2006). Neste sentido, o Programa Nacional de Alimentação Escolar (PNAE), implantado em 1955 e atualmente gerenciado pelo Fundo Nacional de Desenvolvimento da Educação (FNDE), é o programa social mais antigo do país na área de SAN, sendo considerado como uma estratégia para a consolidação do Direito Humano à Alimentação Adequada (DHAA), ao fornecer alimentação de qualidade, de forma regular e permanente, contribuindo com a saúde dos seus beneficiários (SANTOS et al., 2007; BRASIL, 2009; PEIXINHO, 2013).

A importância dos manipuladores de alimentos no contexto da alimentação escolar, mais conhecidos como merendeiras/merendeiros, é legitimada pela proximidade e conhecimento acerca das preferências dos alunos, e a possibilidade de utilizarem a alimentação escolar como espaço permanente de aprendizado (CARVALHO et al., 2008), desempenhando um importante papel na formação de hábitos alimentares saudáveis dos escolares (CAMOZZI et al., 2015). Entretanto, o potencial deste profissional para a educação em saúde, em muitos casos, permanece inexplorado ou não é percebido como uma possibilidade, devido ao não reconhecimento do potencial destes profissionais pelos demais atores da comunidade escolar; a baixa escolaridade; a desvalorização e a sobrecarga de trabalho; o desgaste físico decorrente; e o tipo de capacitação que recebem (TEO; SABEDOT; SCHAFER, 2010; FERNANDES; FONSECA; SILVA, 2014). 
As ações de formação devem sensibilizar e qualificar os manipuladores para a promoção da saúde no ambiente escolar, proporcionando a reflexão sobre seu papel na garantia do direito à alimentação adequada dos escolares e a conscientização sobre a importância da alimentação, não apenas no sentido de atender as necessidades nutricionais, mas também com relação à formação de hábitos alimentares e de vida saudáveis. Para tanto, programas contínuos e permanentes de treinamento, informação e conscientização dos manipuladores devem ser implementados (MUNHOZ; PINTO; BIONDI, 2008; ANDREOTTI et al., 2003; CAMOZZI et al., 2015).

Com base na revisão da literatura, tanto na área de nutrição como na de educação, bem como na experiência da Equipe de Educação Permanente do Centro Colaborador em Alimentação e Nutrição do Escolar (CECANE UFRGS) na formação de atores do PNAE, principalmente na adquirida com manipuladores de alimentos, o presente artigo tem por objetivo propor uma nova abordagem para a Formação de Manipuladores de Alimentos que atuam na alimentação escolar. Espera-se que este trabalho possa contribuir com o aprimoramento dessas ações, fornecendo subsídios que auxiliem os responsáveis pelo planejamento e execução da formação dos manipuladores de alimentos, e, consequentemente, com a melhora da qualidade do PNAE.

\section{Responsabilidades no contexto da formação de manipuladores de alimentos do PNAE}

Segundo a Lei $\mathrm{n}^{\circ}$ 11.947/2009, que dispõe sobre o atendimento da alimentação escolar, a União, por meio do FNDE, entre outras atribuições, tem a competência de prestar orientações técnicas para o bom desempenho do PNAE e cooperar no processo de capacitação dos atores do Programa. Menciona, ainda, que os estados e municípios devem capacitar os recursos humanos envolvidos na execução do PNAE e no controle social, podendo essa atividade ser realizada em parceria com o FNDE (BRASIL, 2009).

A Resolução CD/FNDE no 26/2013, que regulamenta o atendimento da alimentação escolar no âmbito do PNAE, refere a importância da adoção de medidas, juntamente com as escolas, que garantam a oferta de uma alimentação saudável e adequada tanto do ponto de vista nutricional quanto das condições higiênico sanitárias, desde o preparo até o seu consumo pelos alunos (BRASIL, 2013). Entre essas medidas, destaca-se a formação dos responsáveis pela preparação das refeições servidas aos estudantes no âmbito escolar. Já a Resolução no 216/2004 da Agência Nacional de Vigilância Sanitária, reforça o desenvolvimento dessa ação, especificamente quanto às atividades relacionadas ao tema boas práticas para serviços de alimentação, ao referir que "os manipuladores de alimentos devem ser supervisionados e capacitados periodicamente em higiene pessoal, em manipulação higiênica dos alimentos e em doenças transmitidas por alimentos" (BRASIL, 2004). 
De acordo com a Resolução do Conselho Federal de Nutricionistas no 465/2010, que dispõe sobre as atribuições do Nutricionista no Programa de Alimentação Escolar (PAE), destaca-se que este profissional deve: participar do recrutamento, seleção e capacitação de pessoal que atue diretamente na execução do PAE; coordenar, supervisionar e executar programas de educação permanente para a comunidade escolar; colaborar na formação de profissionais na área de alimentação e nutrição, participando de programas de aperfeiçoamento, qualificação e capacitação; orientar e supervisionar as atividades de higienização de ambientes, armazenamento, equipamentos e utensílios; planejar, orientar e supervisionar as atividades desde a compra até a distribuição dos alimentos, zelando pela quantidade e qualidade dos produtos; e, ainda, desenvolver ações de educação alimentar e nutricional para a comunidade escolar (CFN, 2010).

Portanto, a formação de manipuladores de alimentos constitui uma ação integrada e de responsabilidade de diversos segmentos: gestores, nutricionista, setor pedagógico, setor de alimentação escolar, outros profissionais da Saúde (como psicólogos, assistentes sociais, médicos, dentistas), diretores e coordenadores pedagógicos das escolas, entre outros. Considera-se que cada um destes atores ou seguimentos poderá contribuir de formas diversas, em diferentes etapas do processo de planejamento e execução da formação, principalmente, com suas experiências e conhecimentos específicos de sua área. $\mathrm{O}$ estabelecimento de parceria destes diferentes atores, sensibilizados para o trabalho em conjunto, pode auxiliar, em todas as etapas, tornando o processo de formação mais efetivo e integrado.

\section{Aspectos relevantes na formação contínua de manipuladores de alimentos no âmbito do PNAE}

Sabe-se que formações realizadas com os manipuladores de alimentos, envolvidos na alimentação escolar, podem auxiliar no melhoramento da execução do PNAE, uma vez que os conhecimentos e habilidades básicas do público-alvo são aprimorados e auxiliam no desenvolvimento de suas atribuições. As atividades realizadas com os manipuladores devem promover o envolvimento, a postura crítica e a reflexão, visando aprimorar suas práticas de forma contextualizada para o enfrentamento das situações inerentes à sua função (CAMINÉ; RIBEIRO, 2007; SCARPARO et al., 2013).

Algumas publicações apontam dados preocupantes e inquietantes quanto à formação de manipuladores. A deficiência de recursos humanos qualificados, ausência de treinamentos e supervisão são salientados como os principais problemas nas cozinhas (OLIVEIRA; BRASIL; TADDEI, 2008). Andreotti et al. (2003) verificaram que, geralmente, os profissionais admitidos na área são desprovidos de qualquer treinamento em alimentação e nutrição. Além disso, um estudo que avaliou a percepção dos manipuladores de alimentos com relação à produção e distribuição da alimentação, em escolas atendidas pelo PNAE, e seu papel neste processo, observou a ausência de treinamentos sistemáticos para essa população (CARVALHO et al., 2008). 
A importância da realização de cursos e sua frequência também são relatadas. O trabalho que analisou o comportamento dos funcionários de um restaurante antes e após o curso sobre boas práticas encontrou mudança significativa (ANDREOTTI et al., 2003). O mesmo foi relatado no estudo de Cunha et al. (2013), que realizou um programa de intervenção com manipuladores de alimentos de 68 escolas públicas brasileiras. Entretanto, constata-se que para a mudança efetiva de hábitos, são necessários o acompanhamento e a formação contínua e permanente dos profissionais (CUNHA et al., 2013; LANGE et al., 2008). A pesquisa que acompanhou uma unidade de alimentação e nutrição após o treinamento de manipuladores verificou que quanto mais distante da intervenção do estudo (treinamento), maior o número de não conformidades apresentadas. Os autores sinalizam que o retorno gradativo a situação anterior ao treinamento, pode e deve ser contornado, através de cursos frequentes e permanentes (ALVES; ANDRADE; GUIMARÃES, 2008). Portanto, as formações contínuas são indispensáveis à promoção, manutenção e reciclagem de conhecimentos, atitudes e comportamento de manipuladores de alimentos (GHISLENI; BASSO, 2008).

De acordo com Oliveira (2017), as práticas dos manipuladores de alimentos, assim como de outros profissionais da escola, são permeadas por saberes tradicionais e culturais. Por isso, se os treinamentos, capacitações ou formações técnicas não levarem em consideração a construção compartilhada de saberes, de práticas e soluções, eles poderão não alcançar os resultados almejados, como a efetivação de um ambiente escolar promotor de hábitos de vida e alimentação saudáveis.

A formação contínua para os manipuladores de alimentos, que atuam na alimentação escolar, tem como proposta de trabalho instrumentalizar os profissionais para que de forma efetiva e eficiente possam exercer suas atribuições. Para concretizar esta proposta de formação, sugere-se uma prática teórica metodológica fundamentada na Pedagogia Crítica da Educação, que traz como eixo a problematização e como ponto de partida a prática do planejamento participativo o qual possibilita, através das ações, mediações e interações presentes no processo ensino e aprendizagem, um diálogo sobre a realidade. Freire (2005) destaca a importância da relação dialógica, afirmando que o diálogo entre os conhecimentos dos educandos e educadores é fundamental para a problematização de situações reais vividas. Para esse autor, o conhecimento é algo a ser construído na coletividade e no movimento da ação reflexão.

Nesta perspectiva, a formação contínua dos manipuladores de alimentos, ao resgatar os conhecimentos já adquiridos e as experiências presentes no dia a dia, contribuirá para que haja uma maior participação e engajamento destes profissionais tanto nos processos relacionados com a sua formação como os ligados ao seu contexto de trabalho. Piaget (1974) sinaliza que uma aprendizagem jamais parte do zero, sendo importante relacionar os conhecimentos a serem adquiridos as experiências, vivências e conhecimentos prévios dos sujeitos. Freire (2005) também ressaltou estas questões ao contextualizar seu trabalho com a realidade do educando, onde o educador partirá dos 
conhecimentos que o sujeito adquire nas relações sociais e no cotidiano, levando-os ao alcance do conhecimento sistematizado.

A construção do conhecimento consiste no processo individual de construção de estruturas cognitivas, que ocorre a partir da ação do sujeito na interação com o objeto de conhecimento, mas que ocorre no coletivo, a partir das possibilidades de experiências e aprendizagens espontâneas que o meio social, em que o sujeito está inserido, oferece. Por isso, a partir de uma mesma experiência, sujeitos diferentes poderão apresentar construções cognitivas diferentes, pois essas estão diretamente relacionadas com a qualidade da interação, ou seja, do que foi possível ser assimilado por cada sujeito a partir das estruturas que já possuía, assim como dos conhecimentos prévios (BECKER, 2012).

Segundo Becker $(1992 ; 2012)$ o conhecimento se constitui pela interação do indivíduo com o meio físico e social, com o mundo das relações sociais. Neste sentido, entende-se que o conhecimento é construído socialmente, sendo que o tipo de relação que se estabelece entre os envolvidos no processo torna-se fundamental para que a aprendizagem ocorra. Portanto, é necessário considerar a forma de mediação que os responsáveis pela formação utilizam, bem como a opção por uma metodologia que torne a aprendizagem significativa, possibilitando aos manipuladores de alimentos motivaremse a buscar respostas frente as suas dúvidas, construindo novos conhecimentos que os levem a questionarem suas próprias práticas. Ao colocarem-se neste lugar de reflexão e investigação, os manipuladores passarão a assumir um novo papel no processo de aprender, percebendo que o que é assimilado e compreendido provoca inicialmente uma desacomodação, principalmente, de conceitos que antes eram tidos como verdadeiros e únicos.

Para Freire (2005) é necessário conhecer a realidade do grupo que se pretende atingir, para que a partir destes dados seja possível selecionar conteúdos e temáticas que contemplem as questões a serem trabalhadas, organizando uma metodologia adequada à realidade, contemplando assim os objetivos propostos na formação.

Diante disto, ao considerar a importância do manipulador de alimentos como um sujeito ativo e participativo, espera-se a superação dos treinamentos baseados em palestras, nas quais a proposta é transmitir um conhecimento pronto para os manipuladores.

\section{Aspectos a serem considerados no planejamento da formação de manipuladores de alimentos na alimentação escolar}

Ao planejar uma formação deve-se levar em consideração, como eixos norteadores, que a alimentação escolar é um direito dos estudantes e constitui-se como um espaço pedagógico, no qual os manipuladores de alimentos possuem papel relevante, o qual 
deve ser valorizado. Independente dos assuntos a serem abordados, esses eixos devem sempre estar norteando o processo de estruturação da formação (QUADRO 01).

Quadro 01. Eixos norteadores para o planejamento de uma formação de manipuladores de alimentos que atuam na alimentação escolar

Valorização profissional: com destaque para a importância e relevância do trabalho que desenvolvem e suas responsabilidades;

Manipuladores enquanto atores do PNAE: por serem responsáveis pela elaboração da alimentação na escola e sua oferta, devem entender o contexto no qual estão inseridos, conhecendo o funcionamento do PNAE. Nesse sentido, ressalta-se a pertinência de ajudá-los na compreensão de seu papel e dos motivos/importância de seguirem as orientações de modo a ofertar alimentação com qualidade (nutricional e higiênico-sanitária) aos beneficiários do Programa; Alimentação como um direito dos escolares: o PNAE apresenta função estratégica na consolidação do DHAA, ao fornecer alimentação de qualidade, de forma permanente, durante os 200 dias letivos, contribuindo com a saúde dos seus beneficiários;

Alimentação escolar como espaço pedagógico: a escola é reconhecida como um espaço favorável à formação de hábitos saudáveis. $\mathrm{O}$ manipulador pode ser parceiro na promoção de saúde, pois tem papel de educador alimentar, uma vez que oferece as refeições e pode assim estimular o desenvolvimento dessas práticas. Neste contexto, torna-se essencial proporcionar momentos de reflexão sobre a formação de hábitos saudáveis das crianças e a educação alimentar e nutricional no ambiente escolar.

Fonte: Construído pelos autores

Outro aspecto importante a ser considerado é a necessidade de construir um programa de formação, no qual estejam previstos diferentes momentos, coletivos e individuais, bem como que considerem o tempo de serviço dos manipuladores e as atividades de formação que já participaram. Por exemplo, um profissional recém contratado poderá participar de uma formação integradora, que objetiva trabalhar os conhecimentos que já foram abordados com os demais profissionais e, ainda, ambientálo ao local e rotinas de trabalho.

Mesmo em locais onde atividades com os manipuladores já foram realizadas e temas abordados, em outros momentos, é pertinente dar continuidade ao processo de formação, retomando, aprofundando ou contextualizando assuntos já trabalhados. Essa decisão dependerá da necessidade de cada local.

O processo de formação pode ocorrer de diferentes maneiras, apresentando momentos coletivos, nos quais o grupo de manipuladores será convidado para participar de encontros abordando assuntos específicos, bem como atividades individuais, por exemplo, por meio do acompanhamento do dia-a-dia de trabalho, durante uma visita na escola, no qual podem ser fornecidas orientações ao manipulador de acordo com a necessidade real.

No planejamento e execução da formação, pode-se avaliar a possibilidade de propor que os encontros ocorram integrando municípios vizinhos ou da região. Este 
procedimento favorece a partilha das diferentes realidades e estas ações propiciam a troca de experiências entre os participantes, consideradas como fundamental para a motivação à mudança. Além disso, a estratégia de proporcionar momentos de exposição da realidade de trabalho pelo próprio manipulador poderá contribuir para a valorização do trabalho realizado e estímulo para o seu aprimoramento.

Outra alternativa, que poderá favorecer a dinâmica do trabalho, seria convidar profissionais de áreas afins para trabalharem as temáticas que serão desenvolvidas na formação, por serem novas vozes e olhares abordando o conteúdo a partir de diferentes enfoques, como por exemplo: vigilância sanitária, médico, fisioterapeuta, pedagogos, psicólogos, extensionista rural, entre outros. Aconselha-se a participação de profissionais da área de psicologia para auxiliarem no planejamento e execução de dinâmicas, principalmente relacionadas à motivação, à mudança de comportamento e valorização profissional.

A escolaridade dos participantes é outro fator que deve ser verificado e considerado durante o planejamento e desenvolvimento da formação. Vale ressaltar que estudos na área da nutrição verificaram a baixa escolaridade dos manipuladores de alimentos que atuam no PNAE (ANDREOTTI et al., 2003; ALVES; ANDRADE; GUIMARÃES, 2008; MUNHOZ; PINTO; BIONDI, 2008). Neste sentido, considera-se pertinente adequar a mensagem a ser comunicada ao público alvo da atividade, tanto com relação às suas necessidades e interesses, como com relação a capacidade de compreensão e, ainda, a possibilidade dela ser cumprida ou ser colocada em prática pelos participantes (ZIMERMAN, 1993; SANTOS, 2014).

Observa-se muitas vezes como sendo uma dificuldade dos responsáveis pela formação selecionar o que será comunicado, dentro de tudo que se sabe sobre o assunto ou tema, pois considera-se todo o conteúdo como importante ou necessário. Além disso, considera-se como um equívoco presumir que o receptor está pronto, apto e receptivo à mensagem que se deseja comunicar ou, ainda, que todos entendem a mensagem da mesma forma, desconsiderando que uma mesma mensagem pode sofrer distorções ao ser percebida por várias pessoas, simultaneamente, pelo fato de que elas estão em estados emocionais distintos e são portadoras de realidades e vivências diferentes (ZIMERMAN, 1993; SANTOS, 2014).

Adicionalmente, torna-se fundamental a compreensão por parte dos gestores, diretores e de toda a comunidade escolar da importância de todas as questões relacionadas à alimentação no âmbito da escola. Entre as dificuldades na implementação de algumas práticas e mudanças no trabalho dos manipuladores, junto ao PNAE, constata-se a falta de valorização, apoio e, ainda, conhecimento das orientações por parte de alguns desses atores da escola (SCARPARO et al., 2014). Assim, no contexto da alimentação escolar, salienta-se o papel dos diretores das escolas, os quais estão diretamente e diariamente em contato com os manipuladores, podendo ser aliados no processo educacional, supervisionando a prática e retomando aspectos relacionados à formação. Portanto, considera-se pertinente que esses profissionais tenham conhecimento dos 
assuntos abordados nas formações de manipuladores, seja participando das mesmas ou por meio de informativos enviados às escolas, entre outras possibilidades.

\section{Assuntos a serem trabalhados nas formações de manipuladores de alimentos}

Constata-se, na análise das publicações referentes à formação de manipuladores, que na maioria dos cursos realizados com esta atividade profissional, o assunto mais abordado está relacionado ao controle higiênico-sanitário na produção de refeições (ANDREOTTI et al., 2003; FORTES, 2005; ALVES; ANDRADE; GUIMARÃES, 2008; GHISLENI; BASSO, 2008; LANGE et al., 2008; SOARES et al., 2012), embora as temáticas "elaboração de cardápios” (PASSOLI et al., 2006) e "reflexões sobre e práticas do trabalho" (TANAJURA, 2011), entre outras, também sejam encontradas em menores proporções.

Ainda que o tema controle higiênico-sanitário seja essencial e faça parte do trabalho diário dos manipuladores de alimentos, o planejamento das formações destes profissionais, especialmente daqueles que atuam com alimentação escolar, deve ser complementado com outras temáticas (CAMOZZI et al., 2015). Para que este profissional tenha uma formação completa que atenda as suas expectativas e as do PNAE é preciso rever os conteúdos da formação, além de contextualizar, motivar e valorizar o seu trabalho (TANAJURA, 2011; LEITE, 2011).

Oliveira (2017) constataram que os manipuladores de alimentos ao serem entrevistados reconhecem seu papel, na alimentação escolar, de forma ainda tecnicista, como profissionais responsáveis pela produção e garantia de uma alimentação segura, do ponto de vista microbiológico, e saudável. Para a autora, os caminhos para esses profissionais assumirem o papel de educadores alimentares perpassa o empoderamento e a troca de saberes com os demais atores envolvidos na alimentação escolar.

Uma alternativa interessante, na escolha das temáticas a serem trabalhadas, pode ser a construção de uma proposta participativa com os manipuladores de alimentos juntamente com os órgãos executores, na qual serão definidos os assuntos que são pertinentes ou necessários de serem abordados ou aprofundados de acordo com a realidade do local de trabalho. A construção de um modelo de formação, com contribuição e valorização da consulta ao público alvo, proporciona maior chance de êxito e assimilação, por trabalhar demandas específicas apresentadas pelos próprios participantes (LEITE, 2011).

Neste contexto, apresentam-se sugestões de temas considerados como importantes de serem trabalhados com este público, servindo como norteadores das atividades (QUADRO 02). Na definição dos temas a serem abordados deve existir flexibilidade, sendo possível incluir novos assuntos, provenientes do contato com o público alvo, contexto, necessidades e demandas verificadas durante o planejamento, assim como explorar ou adaptar as atividades sugeridas ou já desenvolvidas. 
Quadro 02. Sugestão de assuntos a serem trabalhados com os manipuladores de alimentos que atuam na alimentação escolar

- Alimentação escolar adequada e segura como direito humano;

- Direito Humano à Alimentação Adequada (DHAA);

- Segurança Alimentar e Nutricional (SAN);

- Programa Nacional de Alimentação Escolar (PNAE):

- histórico

- panorama atual

- objetivo

- forma de gestão

- atores envolvidos e suas atribuições

- recursos financeiros

- controle social

- cardápio

- valores nutricionais

- Atribuições dos manipuladores de alimentos no PNAE;

- Valorização profissional;

- Saúde no ambiente escolar;

- Ergonomia e Segurança do trabalho;

- Relações humanas e trabalho em equipe;

- Estímulo à participação no Controle Social;

- Compras na alimentação escolar (desde o processo de compra até a entrega dos alimentos nas escolas);

- Alimentos da agricultura familiar;

- Teste de aceitabilidade;

- Alimentação saudável, necessidades nutricionais e respeito aos hábitos alimentares regionais e culturais;

- Necessidades nutricionais;

- Transição Nutricional;

- Sobrepeso e obesidade;

- Consumo de alimentos industrializados, destacando o teor de gordura, sódio e açúcar;

- Doenças Crônicas Não Transmissíveis (DCNT);

- Patologias relacionadas à nutrição e elaboração de cardápios (Diabete Melitus, Intolerância, Alergia, Hipertensão, entre outras);

- Formação de Hábitos Alimentares;

- Educação Alimentar e Nutricional;

- Importância do seguimento do cardápio;

- Ficha técnica;

- Doenças transmitidas por alimentos;

- Contaminação de alimentos;

- Manual de boas práticas;

- Controle higiênico-sanitário dos alimentos; 
- Boas práticas na produção de alimentos:

- higiene pessoal

- higiene do ambiente

- higiene de equipamentos e utensílios

- potabilidade da água

- controle de pragas

- recebimento dos alimentos

- controle de estoque e armazenamento

- descongelamento

- higienização dos alimentos

- preparo dos alimentos

- distribuição

- controle de tempo e temperatura

- coleta de amostra

Fonte: Construído pelos autores.

\section{Etapas da Formação de Manipuladores de Alimentos}

Ao considerar que a Formação dos profissionais ultrapassa ações que tenham caráter meramente prescritivo ou técnico, é importante ter presente que esta formação, ao contemplar diferentes etapas, ocorre a partir de um processo formativo o qual mobiliza diversos saberes, desenvolvendo competências e habilidades para investigar, compreender e agir conforme as necessidades constatadas. Deve-se ter em mente que para efetivar a formação contínua serão necessárias ações a curto, médio e longo prazo, que estarão contempladas nas etapas de planejamento, de execução e de avaliação.

\section{Planejamento}

O planejamento é uma forma de programar ações indicando as prioridades básicas, os recursos e os meios para se atingir os objetivos, incluindo tanto a revisão das atividades em termos da sua organização e coordenação, quanto a sua revisão e adequação no decorrer de todo o processo. Segundo Vasconcellos (2000, p.79), "Planejar é antecipar mentalmente uma ação ou um conjunto de ações a ser realizadas e agir de acordo com o previsto. Planejar não é, pois, apenas algo que se faz antes de agir, mas é também agir em função daquilo que se pensou”.

Nesta etapa deve-se levar em conta a necessidade de avaliar a realidade com a qual se pretende trabalhar, coletar demandas e apontar necessidades para, assim, propor um plano de trabalho adequado a essas especificidades (FREIRE, 1997). O Planejamento esboçará uma situação futura a partir da situação atual. Por isso, neste momento, será previsto o que, como, onde, quando e o porquê se quer atingir tal objetivo, a fim de garantir a objetividade, a funcionalidade, a continuidade, a produtividade e a eficácia das ações planejadas (VASCONCELLOS, 2000; SCARPARO et al., 2014). 
Cabe ressaltar que, após a análise da realidade e de elencar as necessidades e prioridades, é imprescindível ter clareza dos objetivos e metas que se pretende alcançar com o processo de formação. Os objetivos serão os norteadores do planejamento da intervenção (SCARPARO et al., 2014).

Os responsáveis pelo planejamento da formação devem guiar suas reflexões e ações em cima de três dimensões: Realidade (onde estamos), Finalidade (para onde queremos ir) e Mediação (o que fazer para chegar lá). O Quadro 03 apresenta uma sistematização destas dimensões que compõe o planejamento da formação (VASCONCELLOS, 2000).

Quadro 03. Sistematização das dimensões que compõe o planejamento de uma formação

ANÁLISE DA REALIDADE (realização de diagnóstico)
Conhecimento da Realidade e Necessidades e demandas
- Sujeitos (Quem, para quem - A população alvo do planejamento. No PNAE destacam-se os
alunos, a equipe escolar, os manipuladores de alimento e os conselheiros do CAE)
- Contexto (Onde, quando - Na Secretaria de Educação, nas escolas “x"...)
PROJEÇÃO DAS FINALIDADES (definição dos objetivos)
- Objetivo Geral - expressa a intenção de resolver uma necessidade ou demanda a partir dos
dados levantados no diagnóstico
- Objetivo Específico - definem o que se pretende realizar para alcançar aquilo que está
expresso no objetivo geral
PLANO DE MEDIAÇÃO (elaboração do projeto de ação)
- Definição dos conteúdos e atividades (o que)
- Explicitação do como se pretende trabalhar o conteúdo; quais os procedimentos, estratégias
e técnicas que serão utilizadas (Metodologia)
- Tempo: Quando acontecerá a formação e previsão do tempo a ser utilizado com cada assunto
- Local (onde)
- Recursos: humanos, físicos e financeiros (Com que); Quais os recursos que serão utilizados
para orientar o trabalho
- Avaliação: Definição de instrumentos avaliativos para o acompanhamento das ações do Plano

Fonte: Construído pelos autores.

\section{Execução}

A execução "é o momento de dar andamento às decisões de forma coerente e consistente" (LUCKESI, 2008, p.148), na qual se concretiza o projeto de formação, tendo em vista os objetivos propostos. É a fase que materializa tudo aquilo que foi planejado anteriormente, reforçando a necessidade de um plano de mediação estruturado a partir da realidade e considerando as finalidades a serem alcançadas.

Para que o projeto se desenvolva com eficiência exige-se uma atenção especial às questões de organização, pois sua execução depende muito da forma como as pessoas da equipe de formação interagem, comunicam, trabalham e envolvem-se durante este processo. É importante que ocorram encontros da equipe responsável pela coordenação 
e dinamização, a fim de acompanhar a execução da formação e do que foi planejado, evitando assim falhas no andamento do projeto. A ação de coordenação implica no estabelecimento da organização, na articulação e interligações entre as pessoas, tarefas e funções durante a execução do projeto (SCARPARO et al., 2014).

Para a execução do projeto Moura e Barbosa (2007), recomendam, também, atenção especial aos seguintes elementos: comunicação, cooperação, coordenação, consenso, clareza, comprometimento e conciliação. Estes elementos contribuem para a solução de possíveis conflitos, muitos deles decorrentes de variações que poderão exigir algum replanejamento.

\section{Avaliação}

O processo de avaliação, terceira etapa da formação, está baseado na análise e reflexão de todos os momentos e fatores que intervêm na formação, a fim de determinar a efetividade das ações planejadas e executadas, estando elas previstas ou não no projeto. Portanto, possibilita verificar se os objetivos de aprendizagem foram alcançados, bem como se a metodologia de ensino foi utilizada de maneira adequada para a apropriação de novos conhecimentos. De acordo com Luckesi (2008, p.165), "A avaliação é um ato de investigar a qualidade dos resultados intermediários ou finais de uma ação, subsidiando sempre sua melhora".

Para tanto, a avaliação de um projeto requer a definição de instrumentos que ofereçam informações necessárias para a leitura do processo e dos resultados. A escolha e a aplicação dos instrumentos a serem utilizados dependerão da abrangência do projeto. A equipe organizadora da formação definirá: o método; o que se pretende avaliar (atividades pontuais ou a sua totalidade); o período de aplicação do instrumento escolhido; e os participantes (se será realizada com todo o grupo ou individualmente). Nos instrumentos utilizados para a coleta de dados encontram-se: questionários, entrevistas, grupos focais, observação, entre outros (MOURA; BARBOSA, 2007).

$\mathrm{Na}$ etapa da avaliação, é importante ressaltar que esta, quando associada não meramente ao controle de resultados passa a ser compreendida como um processo de aprendizagem, atribuindo aos espaços de formação um novo sentido, ou seja, de acolher a formação como oportunidade de analisar e refletir a prática vivenciada reconhecendo assim a possibilidade de transformá-la (SCARPARO et al., 2014).

\section{Considerações Finais}

A formação dos manipuladores de alimentos tem como finalidade instrumentalizar os profissionais para que de forma efetiva e eficiente possam exercer suas atribuições, garantindo uma alimentação adequada e segura para os escolares. Por meio do conhecimento adquirido, o manipulador de alimentos pode atuar como protagonista na garantia do direito da criança à alimentação e na formação de hábitos saudáveis, participando do controle social. 
A análise levada a efeito ao longo do artigo conduz a algumas considerações importantes. Talvez a mais relevante seja a necessidade de formar manipuladores de alimentos sob a perspectiva da aprendizagem problematizadora, resgatando conhecimentos já adquiridos e as experiências presentes no dia a dia, constituindo uma proposta mais desafiadora, uma vez que rompe como modelos tradicionais de formação.

Nos modelos tradicionais de formação, observam-se ações pontuais, muitas vezes desconectadas com a realidade do local, com materiais prontos e sendo ministrados no formato de palestras. A contextualização da formação, conhecendo a realidade física e social, abrindo espaço para a reflexão e investigação, torna o processo de aprender significativo, provocando uma desacomodação dos conceitos e com isso espera-se uma mudança na realidade de trabalho.

O papel do responsável pela formação é atentar para a realidade do local e do trabalhador. Não deve existir uma receita pronta ou um programa pré-estabelecido por instâncias superiores. Sugere-se, preliminarmente, um diagnóstico das condições de trabalho e do meio social e familiar dos trabalhadores para depois, realizar o planejamento das ações específicas para o local de trabalho. Cabe salientar, a importância do envolvimento dos diretores das escolas, a fim de dar o suporte no processo educacional, na continuidade dos conhecimentos adquiridos e na supervisão da prática.

Neste sentido, aconselha-se que a formação dos manipuladores de alimentos tenha momentos individuais e coletivos, considerando o tempo de serviço, as vivências e as experiências dos funcionários, abordando assuntos para além das boas práticas na produção dos alimentos.

\section{Contribuições Individuais}

ALSS e PLB participaram da concepção e redação do artigo. EFSL participou da redação do manuscrito. JGV e FCR participaram da revisão bibliográfica e revisão crítica do artigo.

\section{Agradecimentos}

Agradecimentos ao Fundo Nacional de Desenvolvimento da Educação (FNDE) e ao Centro Colaborador em Alimentação e Nutrição do Escolar da Universidade Federal do Rio Grande do Sul (CECANE UFRGS) que proporcionaram condições para a realização deste trabalho. 


\section{Referências}

ALVES LC, ANDRADE LP, GUIMARÃES KAS. Treinamento sobre higiene e controle de qualidade para manipuladores de alimentos de uma Unidade de Alimentação e Nutrição. Higiene Alimentar 2008; 22(166/167):32-37.

ANDREOTTI A, BALERONI FH, PAROSCHI VHB, PANZA SGA. Importância do treinamento para manipuladores de alimentos em relação à higiene pessoal. Iniciação Científica Cesumar 2003; 5(1):29-33.

BECKER F. O que é construtivismo? Rev Educ 1992; 21(83):7-15.

BECKER F. Educação e construção do conhecimento. Porto Alegre: Artmed, 2012.

BRASIL. Constituição da República Federativa do Brasil de 1988. Diário Oficial da União 1988; 05 out.

BRASIL. RDC no 216 de 15 de Setembro de 2004. Dispõe sobre o Regulamento técnico de boas práticas para serviços de alimentação. Diário Oficial da União 2004; 16 set.

BRASIL. Lei no 11.34615 de Setembro de 2006. Cria o Sistema Nacional de Segurança Alimentar e Nutricional - SISAN com vistas em assegurar o direito humano à alimentação adequada e dá outras providências. Diário Oficial da União 2006; 18 set.

BRASIL. Lei no 11.947 de 16 de Junho de 2009. Dispõe sobre o atendimento da alimentação escolare do Programa Dinheiro Direto na Escola os alunos da educação básica. Diário Oficial da União 2009; 17 jun.

BRASIL. Resolução no 26 de 17 de Junho de 2013. Dispõe sobre o atendimento da alimentação escolar aos alunos da educação básica no âmbito do Programa Nacional de Alimentação Escolar - PNAE. Diário Oficial da União 2013; 18 jun.

CAMOZZI ABQ, MONEGO ET, MENEZES IHCF, SILVA PO. Promoção da Alimentação Saudável na Escola: realidade ou utopia? Cad Saude Col 2015; 23(1):32-37.

CANINÉ ES, RIBEIRO VMB. A prática do nutricionista em escolas municipais do Rio de Janeiro: um espaço-tempo educativo. Ciênc Educ (Bauru) 2007; 13(1):47-70.

CARVALHO AT, MUNIZ VM, GOMES JF, SAMICO I. Programa de alimentação escolar no município de João Pessoa, Paraíba, Brasil: as merendeiras em foco. Interface (Botucatu) 2008; 12(27):823-834.

CONSELHO FEDERAL DE NUTRICIONISTAS. Resolução CFN no 465 de 23 de agosto de 2010. Dispõe sobre as atribuições no Nutricionista, estabelece parâmetros numéricos mínimos de referência no âmbito do Programa de Alimentação Escolar (PAE) e dá outras providências. Diário Oficial da União 2010; 25 ago.

CUNHA DT, FIOROTTI RM, BALDASSO JG, SOUSA M, FONTANEZI NM, CAIVANO S, STEDEFELDT E, ROSSO VV, CAMARGO MCR. Improvement of food safety in school meal service during a long-term intervention period: a strategy based on the knowledge, attitude and practice triad. Food Control 2013; 34(2):662-667. 
FERNANDES AGS, FONSECA ABC, SILVA AA. Alimentação escolar como espaço para educação em saúde: percepção das merendeiras do município do Rio de Janeiro, Brasil. Cien Saude Colet 2014; 19(1):39-48.

FORTES HBS. Projeto "Parceiros na cozinha”: avaliação de um treinamento para manipuladores de alimentos das creches de Porto Alegre conveniadas com a ONG Parceiros Voluntários [monografia]. Porto Alegre (RS): Universidade Federal do Rio Grande do Sul; 2005.

FREIRE P. Pedagogia do Oprimido. 43a Edição. Rio de Janeiro: Paz e Terra; 2005.

GHISLENI DR, BASSO C. Educação em saúde à manipuladores de duas unidades de alimentação e nutrição do município de Santa Maria/RS. Disc Scientia 2008; 9(1):101-108.

LANGE TN, GONÇALVES CAZM, CAÇADOR R, ZAGO MJP, MAEDA A. Ação educativa da Vigilância Sanitária, como instrumentos de aprimoramento da qualidade dos alimentos. Higiene Alimentar 2008;22(165):40-45.

LEITE CL, CARDOSO RCV, GÓES JAW, FIGUEIREDO KVNA, SILVA EO, BEZERRIL MM, VIDAL JÚNIOR PO, SANTANA AAC. Formação para merendeiras: uma proposta metodológica aplicada em escolas estaduais atendidas pelo programa nacional de alimentação escolar, em Salvador, Bahia. Rev Nutr 2011; 24(2):275-285.

LUCKESI CC. Avaliação da aprendizagem escolar: estudos e proposições. 19ed. São Paulo: Cortez, 2008.

MOURA DG, BARBOSA EF. Trabalhando com Projetos: planejamento e gestão de projetos educacionais. 3. ed. Petrópolis: Vozes, 2007.

MUNHOZ PM, PINTO JPAN, BIONDI GF. Conhecimento sobre boas práticas por parte dos manipuladores de alimentos na rede municipal de ensino. Revista Higiene Alimentar (Botucatu) 2008; 22(166/167):29-31.

OLIVEIRA MN, BRASIL ALD, TADDEI JAAC. Avaliação das condições higiênicosanitárias das cozinhas de creches públicas e filantrópicas. Cien Saude Colet 2008; 13(3):1051-1060.

OLIVEIRA IG. Alimentação escolar no discurso de manipuladores de alimentos de escolas brasileiras [dissertação]. Programa de Pós-graduação em Nutrição e Saúde. Goiânia (GO): Universidade Federal de Goiás; 2017.

PASSOLI A, MENEGAZZO M, HEIDRICH D, MARCON MC. Oficinas de formação em nutrição para merendeiras e professoras da creche São Francisco de Assis. Extensio Revista Eletrônica de Extensão 2006; 3(4). Disponível em: https://periodicos.ufsc.br/index. php/extensio/article/viewFile/5590/5077

PEIXINHO AML. A trajetória do Programa Nacional de Alimentação Escolar no período de 2003-2010: relato do gestor nacional. Cien Saude Colet 2013; 18(4):909-916.

PIAGET J. Aprendizagem e Conhecimento. Rio de Janeiro: Freitas Bastos; 1974. 
SANTOS LMP, SANTOS SMC, SANTANA LAA, HENRIQUE FCS, MAZZA RPD, SANTOS LAS, SANTOS LS. Avaliação de políticas públicas de segurança e combate à fome no período 1995-2002. 4 - Programa Nacional de Alimentação Escolar. Cad Saude Publica 2007; 23(11): 2681-2693.

SANTOS JTG. Comunicação e transmissão de mensagens em nutrição: fundamentos, teorias e práticas. In: Galisa MS, Nunes APO, Garcia LS, Chemin SM. Educação Alimentar e Nutricional: da teoria à prática. Vila Mariana, SP: Roca, 2014.

SCARPARO ALS, OLIVEIRA VR, BITTENCOURT JMV, RUIZ ENF, FERNANDES PF, ZYS JZ, MOULIN CC. Formação para nutricionistas que atuam no Programa Nacional de Alimentação Escolar: uma avaliação da efetividade. Cien Saude Colet 2013; 18(4):10011008 .

SCARPARO ALS, BALDASSO PL, LOPES EFS, VENZKE JG, ROCKETT FC.

Material orientativo para formação de manipuladores de alimentos que atuam na alimentação escolar. Centro Colaborador em Alimentação e Nutrição do Escolar da Universidade Federal do Rio Grande do Sul (CECANE UFRGS). Fundo Nacional de Desenvolvimento da Educação (FNDE). Brasília (DF): Ministério da Educação, 2014.

SOARES LS, ALMEIDA RCC, CERQUEIRA ES, CARVALHO JS, NUNES IL. Knowledge, atitudes and practices in food safety and the presence of coagulase-positive staphylococci on hands of food handlers in the schools of Camaçari, Brazil. Food Control 2012; 27(1):206-213.

TANAJURA IMPC. Acepções de merendeiras sobre o Programa Nacional de Alimentação Escolar em um bairro de Salvador, Bahia [dissertação]. Salvador (BA): Universidade Federal da Bahia; 2011.

TEO CRPA, SABEDOT FRB, SCHAFER E. Merendeiras como agentes de educação em saúde da comunidade escolar: potencialidades e limites. Revista Espaço para a Saúde (Londrina) 2010; 11(2):11-20.

VASCONCELLOS CS. Planejamento Projeto de Ensino-Aprendizagem e Projeto Político-Pedagógico. 7.ed. Cadernos Pedagógicos do Libertad-1. São Paulo, 2000.

ZIMERMAN DE. Comunicação. In: Zimerman DE. Fundamentos Básicos das grupoterapias. Porto Alegre: Artes Médicas, 1993. 